\title{
Need for integrated care to homeless people in community
}

\author{
Martina Zakova* and Daniela Stryckova \\ Trnava University in Trnava, Trnava, Slovakia
}

\begin{abstract}
This paper focuses on marginalized clients who are often condemned for their lifestyle. Because of their way of life and community approach, they need help from several experts to solve their living or social situation. Interdisciplinary cooperation is therefore highly beneficial for the clients. However, it is more effective if integrated care exists in the community where these clients live. The aim of this paper is to find out the situation with the integrated care for homeless people in communities. We used semi-structured interviews. We interviewed 7 social workers who work with homeless people directly in the community where these clients live. We also discuss what experts are needed in this field, and we justify their necessity. Research results show that social workers' opinion is that integrated care directly in the community, where homeless people are, would be very helpful since homeless people are afraid to ask for services. Social workers would welcome if experts were willing to work with them directly with clients in the community. They also consider that their clients need hygiene centres and leisure activities. Conclusions - integrated care for homeless people is needed in communities. The results can serve as a description of integrated care in community to provide the best care for people who need their help.
\end{abstract}

\section{Introduction}

The principal topic of this article is the need for integrated care to homeless people in the community from social workers' point of view. Despite the fact that social work with this marginalized group is considered to be a long-term realization, there are only a few researches in Slovakia. This was also a reason for carrying out our research.

Homeless people belong to marginalized groups in some way in each country. Marginalized people are perceived as marginalized because of many things, e.g. because of their gender, race, nationality, their ethnicity, religion or economic or social status in society where they live. Marginality is a concept, which is defined from several points of view. We have chosen those definitions that best explain the term "marginalized groups" and directly relate to the homeless group we have chosen.

Robert Park first introduced the concept of marginality in 1928 with an essay. According to him, the "marginality" is a lack of integration and the status of an "outsider" with respect to dominant cultures[1].

Since that time, the use of the term "marginality" has flourished and the concept has been broadened and diffused. Marginalization relates also to economic area, so it can mean that a marginalized person could be seen as unimportant person in the society. Aisu

\footnotetext{
* Corresponding author: martina.zakova@truni.sk
}

(C) The Authors, published by EDP Sciences. This is an Open Access article distributed under the terms of the Creative Commons Attribution License 4.0 (http://creativecommons.org/licenses/by/4.0/). 
(2015) also states that marginalized groups are excluded from the prevailing protection and integration systems, thereby limiting their survival possibilities and means. In the area of marginalization many different aspects and issues have to be addressed such as discrimination, racism, poverty, globalization, immigration, social security, social welfare, health and human rights [2].

In our research, when we write about marginalized groups we mean different groups of people within a certain culture and context, experiencing risk of being subjected to multiple discrimination due to the interplay of different personal characteristics or grounds, such as sex, gender, age, religion, health status, education or income, or living in various geographic localities. These people face common social, economical and individual problems. According to these definitions we can see that the list of potentially or actually marginalized individuals or groups is extensive - ethnic minorities, disabled persons, ex-prisoners, drug users, sexworkers and homeless people, etc. These people face social, economic and individual problems [3].

We decided to focus on one group from the marginalized - to homeless people because they are extremely marginalized not only from the government, but also from whole society, and because they are an extremely diverse group of people. Individuals who are scattered around different parts of the city, as well as people living in a small community of homeless people stay out of the sight of majority of population. This marginalized group experiences not only problems of homelessness and meeting basic needs. They also face the issue of ethnicity and nationality (including Roma and foreigners coming from different countries, especially from Romania), sexual orientation and identity, dependencies, family-related problems. This group includes also vulnerable people, such as seniors and young adults, lonely women, people with severe health problems (either psychologically or physically restricted), borrowers and dealing with earning and selling materials, with sexual services.

Aim of the study was to explore how social workers perceive the need for integrated care to homeless people in community. We focused on how they perceive community service provision for their clients. We also ask them how integrated care in community should ideally work, what services are most inaccessible to their clients and what client needs cannot be saturated within available services. We ask them what structural obstacles they meet and what services they think are the most inaccessible. We also ask them what kind of care they think is necessary for their clients in the community and how they perceive this care, if there are all of needed services and professionals.

\section{Homeless people}

As mentioned above, homeless people are among the marginalized groups. Homelessness means that home is absent; it is characterized as an exclusion from the physical, legal, and social domain of an apartment. Homeless people are not only people visible on the street, in dormitories and shelters, but also those who are hiding, living in different cottages, abandoned, empty buildings, under bridges, etc. In the category of homeless people or people at risk of homelessness, we can include people without a shelter, without a flat, and persons who live in insecure and inadequate housing [4].

Homeless people are not a homogeneous group. They can have a variety of causes for homelessness. Homelessness, as a form of extreme social exclusion, can be seen as the most visible peak of a much deeper submerged poverty glacier. Hradecka with Hradecky even claim that homelessness is the worst expression of social exclusion [5]. Stanoev states that it is primarily a consequence of inequality in society. It can be preceded by series of individual's failures to solve their situation, or disruption of socialization already in the 
teenage years, respectively even childhood. Both planes cannot be understood as standing against each other, and both things usually work together [6]. Most of homeless people have basic education, as well as experience with staying in constitutional facilities, or are from incomplete families. However, even middle-class individuals are not completely protected from homelessness. About $20 \%$ of homeless people have secondary education and a small segment of this population has university education [7-9].

Homelessness is a very destructive life experience in many ways. Homelessness results in worsening of health status [8] and therefore Stanoev states that the introduction of health care as part of social services for homeless people can be a matter of survival. Dependencies may be the result of homelessness (but also its cause). Accepting a homeless identity is important not only in terms of physical, but also psychological survival, so the life of homeless people appears to be unbearable [6].

Homelessness is a serious issue for society as a whole, and thereby in its solution a significant role should be played by society and, above all, by the state. Unfortunately, in Slovakia there is no definition of homelessness or homeless people in legislation. This situation affects the recognition of the problem, the availability of services and rapid rehousing [4]. Some specific forms of support are defined in the Act on Social services. Social services for homeless people have to be arranged by regional governing bodies or municipalities [10], but the main resolvers of this issue are various non-profit organizations and charities in our country. Social workers most often work with homeless people in these non-profit organizations and charities, which provide most of the social, financial or other assistance. These organizations also seek assistance from the European Union, from the society as a whole, as well as from regional governing bodies, and municipalities.

Social workers working with homeless people are those who, according to Rhodes, work in the field while trying to change the client's behaviour. They do this directly, or through education, enlightenment and community prevention, or indirectly (by distributing clients, that is, by recommending the client to other institutional or residential services that provide services in the community) [11].

Homeless people can have problems with visits to medical doctor, psychologist or other professionals therefore integrated care directly in the community where these marginalized people live is more appropriate for them.

Integrated care is an evolving area whose essence is to meet people's needs in one place. It can be provided in a variety of ways, depending on who is the provider, what kind of care is provided, where care is taking place, and how the services are coordinated [12]. Integrated care is a comprehensive care, which involves health, social care, etc.

\section{Research methodology}

We used qualitative research strategy. According to Hendl, qualitative research provides us with more detailed information about the issue under consideration. Its disadvantage is that it cannot be generalized for the entire population [13].

The main research question of this research was - "What is the need for integration care to homeless people according to social workers?" This main research question was divided into 3 partial questions:

- PRQ1: How do social workers perceive the need for services for their clients in community? What structural obstacles they meet and what services are the most inaccessible.

- PRQ2: What services are needed for their clients in the community?

- PRQ3: What should integrated care look like? 
A semi-structured interview scheme was designed to obtain information about participants' experiences with integrated care to homeless people. Open-ended questions focused on how this integrated care is perceived and if there are all of the needed services and professionals.

The research sample was composed of social workers working with homeless people in a community. In Slovak Republic, majority of social workers work with homeless people directly. These social workers visit their clients in an environment where they are usually located, where they live and where they have found shelter or temporary housing. We used exponential non-discriminative snowball sampling methodology. Our participants work in two cities in the Slovak Republic. We interviewed 5 social workers and we found that the answers repeated. Consequently, we had another 2 interviews. We understood that we did not find out anything new, thereby we stopped collecting data, so it means that a total of 7 interviews were conducted. Interviews lasted approximately for one hour. All interviews were taped and then transcribed. Analytically open coding performed data analysis [14]; all coding was done in the software Atlas.Ti. Another researcher checked the accuracy of coding. Creation of categories was used after the encoding of all data.

\subsection{Interpretation of key categories}

After analyses, 113 codes were identified. The identified codes were then included into 6 main categories: homeless people - their vulnerability and strengths, services that sufficiently cover the needs of clients, services lagging behind client needs, current efforts to improve social services for homeless people, ideal future of social services for homeless people and the importance of professional development of workers. Interpretations of categories responding to partial research questions will be interpreted herein.

\section{Homeless people - their vulnerability and strengths}

According to the participants, their clients in the past have fallen through a certain safety net of the company until they find themselves in a vicious circle from which they do not know how, or are not able, to break free. The biggest obstacle to getting out of the situation is the vicious circle of debt and execution. In particular, they are debts on health insurance, which is obligatory in Slovakia. These debts are of low-income or without income persons (e.g. the amount of the subsistence minimum $210.20 €$ per an individual or welfare benefit $64.70 €$ per an individual) which are not payable and consequently the execution is often increased to thousands of euro. The problem also arises with the access to health care, which is due to debts in the insurance company. Thereby health care is limited exclusively to saving life. “... but by not paying health (insurance)... Well, maybe in this is the question what to do with them, because ... Mm, some people would go to work, but when they realize that... How much I have both debts and executions, and arrears... I do and they will tear everything away, so why (try and work). What about it, but...?" (participant \#3). Finding permanent work with a contract is not motivating, as the executor leaves only the minimum subsistence figure to the debtor. Therefore, these people prefer to choose unemployment or undeclared work, with non-performing debt increasing steadily. People with long-term health problems are the most vulnerable.

People without their own homes find themselves in a situation where, for larger changes in life, they do not have the same starting line as the majority of society: “... and then work, I think. Because they often have the problem that they do not live, they live on squats. So then they are hard to employ. Not because of the homeless status, but because... Imagine that you work 8 to 12 hours somewhere and don't sleep warmly in your bed at home, you don't have saturated basic needs, so..." (participant \#1). The basic thing such as how to process and 
store personal documents is also much more demanding without shelter and requires a lot of motivation.

They also face significant stigma and discrimination in the area of services, but also on the part of society. It is a usual situation when social workers advocate a client in a situation where: "Healthcare professionals have come, so just...(They say:) This one? We already know him and he runs out of the hospital. So then they see them already negative... Even the cops were uncooperative. They also mumbled that we were calling the ambulance here and if there were an acute case, they would be late! And we are to take it home" (participant \# 4). People with psychiatric diagnoses, addictions, and people with severely neglected sanitary conditions face an even greater barrier.

Participants also see the possibility that their clients creatively invent how to meet their basic needs. This is despite the fact that they are outside the majority standards and that the services are inadequate in some areas. "And they are already travelling then, but ... they sleep in trains, squats" (participant \# 1). Many are self-contained and innovative in their area of finding out-of-system resources that inevitably cover their basic needs and develop the social skills that are not common in the majority - how to find a place to sleep at night, how to get money and food, tobacco, clothes, some benefits in services and so on.

\section{Services that sufficiently cover the needs of clients}

Our participants see an effort to cover basic life needs, resp. some basal network of help for their clients, as the very basis of the existing daytime or night time social services: "I perceive it positively, because for these people there is definitely the need to have a service and maybe a sort of primary safety net. They find themselves in streets who to go to. Indeed, they are provided with such a foundation" (participant \# 7). It is therefore mainly a refuge, food and people to whom assistance or advice can be sought.

Field service exists for clients who do not want or cannot attend the services. It is based on eliminating the risks associated with homeless life: "Then such harm reduction is the basis we have in winter, especially for clients who are outside (without shelter). I think this is well secured because they mainly need to warm up with something" (participant \# 6). It is obvious that respondents are trying to focus their programs on the current needs of clients and constantly review them based on new objective information and clients' statements.

Providing social counselling that takes into account the needs of clients is an important part of social work for social workers. "I think that to have a day centre is enough to do this here... that what we know... a solution, a search on the internet or some kind of call... that I think is well secured if clients need some benefits or placement, posts, I don't know, anything... That's what they need"' (participant \# 7).

\section{Lagging behind clients' needs}

Given the critically and humanist thinking of the participants, it has proved to be the richest area of lack of services. The voice of solidarity prevailed among the participants. They named problems that are caused by diverse human factors, even those that are so complicated that their solutions are not yet offered. "... I would say housing, because it is not enough even for the majority of society, so for them (homeless people) at all..." (participant \# 3). The solution to homelessness as such, according to them, provides an affordable and dignified housing alternative. More dignified than the only truly low-threshold dormitory in the capital whose capacity is 200 beds in one larger and one smaller room and without the possibility to be there in daytime. In another city, social workers point out the problem that only 
residents of the city are entitled to a low-threshold overnight accommodation, which they consider unfair.

Participants stress that the biggest drawback in their city is insufficient service in the city compared to the number of people who need it. "I see services for homeless people as insufficient. With as many homeless people as they are, there are few services... This is a crazy number (of clients) and then hard work is good" (participant \# 2). These include the number of hygiene centres, the range of field services, day centres and dormitories within a reasonable reach, as well as a sufficient number of beds, sufficient space for oneself and safety. "Hygiene centres are still in very few places. There are still areas where there is nothing, only that people (homeless) would migrate, which in turn people (passengers) don't like on buses" (participant \# 4).

Even the most vulnerable of the homeless, for whom street life is too demanding, do not always have the right to dignified conditions. "I also encountered a barrier in finding facilities for seniors, even though the client relies on social services but has a low pension. The placement chance really is low, almost none. At the same time a residential facility would be the most helpful for some, where one would be able to satisfy their needs while tackling homelessness" (participant \# 5).

However, according to the participant, systemic solutions to this topic and ending homelessness are not very much looked at in the Slovak Republic. "And secondly, homeless people are not even defined in the law (i.e., all laws as such), which is also a big problem" (participant \# 2). In the absence of a clear name for the problem, there is no system plan to solve the problem, thus creating room for injustice. "The argument that human rights are violated is that... The value of that statement is zero. What seems crazy to me, and yes, if a group of lawyers come here to mow the machete around, then there may be something in the matter. Sometimes I think why I have chosen this (social work) and not something better (laugh). Or something in which one would have more weight (laugh)" (participant \# 2). A change in the quality of life needs to be achieved across the legal level, which would ensure law enforcement for the entire homeless population.

Debts are proving to be an important factor in solving many problems. Despite the tool called personal bankruptcy, the solution is still a lengthy process, while, in social services the basic legal counselling in the area of debts is replaced by social workers.

Health care for homeless people is usually a major problem. Health insurance is compulsory for every citizen. Homeless people, together with the loss of income, also lose their ability to pay this compulsory insurance, and so their debt to the insurance company continues to grow up to the retirement age. They are entitled only to life-saving medical operations. As most clients have these debts, preventive and standard healthcare for homeless people practically does not exist. Therefore "it would be nice if we had a doctor in the field, for example, or a person who can at least assess the condition" (participant \# 5). The work of health care professionals (doctors or nurses) is also very necessary in low-threshold social services, because in terms of barriers these services are most accessible to homeless people. As claimed by the participants, despite the demand, there is a shortage of health care professionals in social services. Social workers or charity workers are therefore also trained in health care to represent their work.

As the services focus primarily on meeting basic needs, space for above-standard enjoyment and experience is in the background. Participants warn that their clients would be well off.

Participants agree that the most vulnerable clients are those with mental illness, ill seniors and people with addiction, or a combination of these problems. They need more intensive social work, accompanying, integration programs, the greatest possible availability 
of services without unnecessary barriers, and more rapid action by public authorities when decisions are needed.

\section{Current efforts to improve social services for homeless people}

Flexibility to meet the changing needs of clients is, according to respondents, the basis for quality service: "The good point is that at least we do not forget and try to keep it up to date, to keep in mind the current needs. And I think there are such basic needs that we think of, and then those that have occurred with them over time" (participant \# 3). The needs of clients in this case are also closely related to the risks they face in streets. "And what I perceive positively is that in the winter months the dormitory is already open from $5 \mathrm{am}$. And even last year it was so that when the frosts lasted longer, at the instigation of charity and city workers, it was still approved to stay there longer" (participant \# 6). The needs of clients are therefore variable and it is necessary to react promptly to them.

Naturally, the practice and the needs of clients that a particular service cannot meet have led respondents to build relationships with other actors who either directly work with this target group and are in favour of it, or are simply inevitably necessary partners. Such actors are, for example, other social services addressed to the same target group, or different government departments and institutions. Respondents perceive this area as a major challenge and long-term struggle, with both good and less good results. "But I do not know if those actors are ready for it and whether they want and do not take the cooperation personally, that they are failing somehow, or that we consider them incompetent, because we try to fight for clients and do not know if they can" (participant \# 7). Good relationships are the key factor of working together to help clients. However, they are based on human relationships that are fickle and social workers must actively seek to build them. As the respondent states: "We live in a golden age of friendship and openness (laughter), at least as far as the organization is concerned. When I came to this organization, there were lonely wolves with whom no one was friends or with whom we did not even want to be friends. We did not sell any information or help so I appreciate that we can already openly communicate between organizations, even consult, help or deal with a client. I am very pleased about that". (Participant \# 2).

\section{Ideal future of social services for homeless people}

From a broader perspective, the first prerequisite for a well-functioning comprehensive service for homeless people is a state and legal solution. Respondents see this as basic deficiencies. From the fact that homeless people are not even defined in the law, to the fact that the financing of services is not enforceable: "That you have no place to claim it at all" (participant \# 2). Thus, the state should have a plan to address the prevention and consequences of the loss of home (as it is a human right) and therefore there should be a well-planned plan for funding such programs. There is an obligation for cities to contribute to daily low-threshold centres (part of the social services for homeless people). However, nothing obliges them to support specific programs from a wide range. This is a problem when working with the so-called "unpopular" target groups, and law should change this in particular.

Other professionals (other than the so-called helping professions) are lacking in homeless services. If homeless people were also strongly motivated to use some of the standard services for the public, they would first have to overcome many human, legislative and practical barriers. Therefore, according to the participants, it is important to bring these services closer to the level that is available for them. "... that the medical staff in the hospital would not 
have to be so involved, that if it is sometimes a problem for them to treat the homeless, maybe there is a mini medical facility dedicated only to them... (homeless people) that perhaps they should not be ashamed to go to the doctor" (participant \# 1). The spectrum of services should also include specialized healthcare or nursing facilities to prevent the aggravation of health problems that are often the result of living in difficult living conditions or outdoors in all weather conditions.

All respondents agree that, at the level of social services, cooperation between programs is crucial for the welfare of clients. "Different co-operation with all those involved or affected by the homelessness phenomenon would help. Working in collaboration would bring better results and better help to the client." (Participant \# 6). It is not easy to establish these relationships, but it is all the more important.

Some ideas for improvement also arise when working directly with clients. For example, services could also be tailored to the needs of clients, which are very diverse, e.g. also given the length of life, spent homeless. "I would still like to have the services set up not according to where I (as a social worker) most like it, but according to when the client needs it. If it had different degrees, it would be great. Degree according to the level of support, for example, that a day-centre would only provide services to people with a low level of support. So, there would be some basic counselling and services that they (clients) somehow enjoy. Great, and then we have the capacity to take care of people who have a high level of support. These are people who need some social assistance or more support. So, distribute it." (Participant \# 2).

Something that is not a priority in services in Slovakia is a certain mental enjoyment and active relaxation of clients. Our participants say that the area of leisure activities is overlooked, but may be important for clients. "I don't know how it is in the daytime centre with free time activities... because, in my opinion, it's a good thing to relieve or to forget your (life) condition a bit. A little bit of endorphins into the brain that: Eh, I'm going to play football! Or something like that." (Participant \# 7). It is also important that they are given the opportunity to realize what they are good at, such as: "Something like developing skills would also be great, and it does not matter whether it would be manual, that how to secure a house or just something to improve. And often they are people who are trained or interested in something" (participant \# 3). Social workers create such activities for clients, but from the perspective of participants, it would be desirable that there would be more opportunities for the development of interests and skills.

In addition, one of the participants also points to the therapeutic potential of the group that day centres could offer. "But I think it would be nice to talk to at least someone, to listen, to tell your story or to hear some others and compare it. Find that: oh, I'm not that bad, or I can advise you. I was in such a situation and I know what helped me." (Participant \# 7). Another participant draws attention to therapeutic work with an individual: "... that would be therapy or some guide to family relationships and social skills. This is such a difficult topic." (Participant \# 4). For clients to be able to work on their life changes, it is essential that social workers can handle client's motivation in the counselling process. "It would motivate them to do something with their lives." (Participant \# 4).

Social workers also pointed out the importance of combining the provision of Housing First programs or affordable housing in combination with the client's cooperation with a social worker in the integration process. This should be the way out of homelessness, i.e. ending homelessness.

The opportunities and relationships that homeless people have to offer right where they live would really make life on the street easier and give them a sense of usefulness. "And something like community work, that would be great. That people are as if connected to the social environment in which they live with their neighbours and can get along. As an added 
value and be mutually beneficial" (participant \# 6). Therefore, working with the public and demolishing prejudices and stereotypes, as well as emphasizing the values of humanity and solidarity, are also important for social workers.

\section{The importance of professional development of workers}

Work with this community of clients requires that social workers plan and get to know their clients' current needs and have good communication skills. “... by providing them (needs) according to (professional) possibilities and according to the rules of interviewing and contact with the client so that there is no charity or manipulation again... I see a clear progress in it, and that the foundation there is good." (Participant \# 7). It is therefore important for the client's development that the social worker does not fall into the support of dysfunctional behavioural patterns, maintains professional principles and vice versa, supports motivation in the process of internal change of the client. For example, by actively involving him in all activities associated with it.

Social workers are forced to be multifunctional workers for their clients. Get into the organization of the workers, for example, from the field of health, law or otherwise specialized social worker is not easy at all. Social workers do not feel comfortable in providing a service outside their field due to the fear that they may not perform enough professionally. "But he is a social worker who is trained more to work with clients who are drug, alcohol and other substance users. We have such a target group that has everything there (diverse issues). We had both children and youth, and it is difficult to cope with." (Participant \# 5). On the other hand, it happens that "In fact, almost every service has social counselling, but the results do not speak much about it. (Laughter) Probably ..." (Participant \# 2). The quality of service is determined by the professionalism and diverse specialization of its employees. What would improve existing social services would be a greater specialization of social work professionals and hence a greater specialization of services, e.g. for people with mental illness, for working with the family, or for drug users and people with addiction who need intensive specific assistance. Therefore, it is necessary that the personnel selection reflects the needs of the clients and that they have room for professional growth and specialization.

Health or legal services are most important for homeless people: "well, a set of professionals from other industries should be there. Well, surely there is something from the health service, because it is the most common problem. I mean a surgeon, a psychologist, even a psychiatrist, because that's also a very common problem. Clients also often want legal services." (Participant \# 4).

\subsection{Discussion}

In order to ensure that services for homeless people are effective and reflective of their needs, social workers should in particular be guided by the basic concepts, objectives and conditions of the services in the law. This should be a basic ground to be able to advocate and argue for the rights of clients and to demand, for example, financial support and prevention support.

Our participants said that being a homeless person is by oneself quite difficult, but access to health care is even more daunting. Homeless people also have many health problems. However, health barriers to access and minimal health care are worse than bad. Health insurance debts and insolvency represent significant barriers to achieving the necessary healthcare. In addition, health care providers often regard homeless people as an abusive system, and these attitudes determine care. Martin's study has the same findings [15]. 
On this basis, the most frequent requirement was that in the context of comprehensive services, financially more affordable housing, city dwellings and the like can help to prevent homelessness. Equally, tackling homelessness, as a phenomenon with its own and secondary consequences, is seen by social workers as social housing coupled by an intense specialized program that leads to the integration of this diverse marginalized community into the majority.

The services provided should meet in particular the condition of availability for all, i.e. directly within the reach of the community, in each urban area and should provide dignified conditions for everyone and meet basic needs, eliminate risks. Field services should focus on those who, for various reasons, do not reach existing stone services and should address minimal risk-of-life risks in the street.

The absolute essence of complex services should be the principle that they should respond sensitively to the needs of community and turn their services over time. They should be based directly on the voice of the community. Therefore, it is important to promote appropriate services. According to social workers, the quality of services should also be based on the high level of professionalism of the staff of all services, thus helping clients to achieve the services they are entitled to. It would also make cooperation on the network more efficient. You often depend on cooperation.

Blue-Howells, McGuire and Nakashima found that the vulnerable population did not have access to critically needed health care. The studied social workers have said that ideal care for their clients will not work without intensive collaboration with other disciplines, such as nursing, and medicine [16], and our participants added also a national legislation.

Social workers should always try to respond to the needs of their clients and that is why some organizations have projects involving other professionals as social workers because they perceive that integrated care is needed. The needs of clients were evaluated basing on interviews during which there was a demand for legal and health issues. At the same time, obstacles (objective, subjective) were identified that prevented clients from visiting, for example, medical procedures. External experts in a client's natural environment have various benefits. In the first place, clients receive a funded response and at the same time can gain more confidence in other professionals, in the aid system, which they will be forced to use it if necessary.

Establishing cooperation with the necessary experts has been and is still very complicated. The level of cooperation with external experts is also limited by their will and leisure time, which they can invest in clients of the association, clients who do not directly fall into their work areas.

A big hurdle is also the higher threshold that clients have to overcome, but they are often hampered by subjective reasons for which they do not want or cannot use such an overburdened service (fear of authorities, negative experience, etc.). At the same time, there are objective obstacles, notably the lack of personal documents (such as an identity card and a health insurance card) and existing debts in health insurance. A homeless person is automatically refused to provide state-guaranteed health care if he has difficulty paying health insurance. Such homeless person is provided only with the necessary medical assistance in a life-threatening situation. It is intended only for the maintenance of human life functions. In conclusion, we see major shortcomings in the interconnection of social and health services, which are sectorally confined. There is currently no flexible solution to provide social-health services and forms of assistance in general, and not just socially vulnerable groups such as drug users or sex workers.

According to our experience, homeless people, sex workers and drug users have many bad experiences with different services or police and try to avoid them, even when they really need it. It follows from the above that a cross-sectorial approach, i.e. the cooperation of 
several experts, is necessary to achieve the appropriate level of care. Randolph, Blasinsky, Leginski, Parker and Goldman in their publication state that integrated systems could serve for accessible, available, appropriate and accountable for homeless people who need services [17].

Social workers also should point out the importance of dealing with marginalization by advocating, influencing public policy, and strive to become more aware of the factors that contribute to marginalization.

Social work with homeless people has many specifics, including reconciliation with the homeless destiny making this life more enjoyable, while reducing the possibility of returning to other life. In social work, it is important to strive for dignity, albeit in dealing with the client, or in trying to ensure better and more dignified living conditions. For social work as such, however, it is important that there is also an alternative to building important life conditions for the homeless not only theoretically, but also in relation to the practice of social policy. Social work with homeless people should be based on the creation of a supportive sociotherapeutic relationship, based on the client's acceptance of his/her situation. It creates the opportunity to, at least partially, improve the life conditions of a client from this target group and responds to the ethical principle of self-determination. Homelessness is not conducive to maintaining solid social relationships, it is not appropriate to maintain a stable job, as homeless people lack the space to relax after work and get enough strength to work the next day. Stanoev considers it important to emphasize and reflect the structural conditions of social work with this social group and try to change it [6]. Only changing these conditions can create more room for developing methods for the full reintegration of homeless people.

\section{Conclusion}

Our participants cite a number of weaknesses of homeless people that make their lives in society more difficult, but they also mentioned a few positive things to build on (e.g. a creative approach to meeting basic needs). Participants state that their clients have a difficult situation also with the access of some professionals to them and thereby they do not have basic care.

Participants positively rated the provision of services that cover the basal needs of their clients however, the shortcomings in the care of their clients have been mentioned several times. Suitable accommodation proved to be the most important. However, there is a problem in Slovakia to find a suitable affordable accommodation for people who are employed because apartments are very expensive compared to wages, and there is insufficient number of rental apartments. Municipalities have several so-called social housings available to its citizens who find themselves in a difficult situation, but this housing is not enough and therefore not allocated to homeless people. If they were also allocated to homeless people who often do not have a stable income, they would not be able to pay for the apartment. With housing, however, there would be fewer people without stable work. The striking finding is that our participant has a problem with equipping the placement of their clients - seniors in the senior facility due to a low pension.

Major problems are also associated with the inability to pay health insurance, which means that clients are not provided with standard health care. Given this, participants would welcome a doctor to go with them in the field. However, the situation in the healthcare sector in Slovakia is not good. We have a shortage of doctors and nurses who go abroad because of higher salaries. In such a situation, it is unrealistic to expect health care professionals to go out to visit people who are perceived negatively, although our participants have stated that the existence of a homeless medical facility would improve the accessibility of health services.

More accessible services for homeless people and services without unnecessary barriers would improve the current situation. Participants would accept if they could also provide 
their clients with the possibility of leisure activities through which they could also satisfy cultural, sporting or other needs, which is also important for them. Participants see a change in our legislation, in defining the conditions and funding of all the necessary social services for homeless people, in greater flexibility of state authorities and in the provision of social services, so that they have the least possible obstacles when trying to change their situation and get off the street.

As we can see, the situation in providing care for homeless people in Slovakia is not good, and services are not networked. Cooperation is only between social workers, but there are no other professionals who are needed. Our participants reported missing medical professionals and lawyers. Homeless people have barriers to go to professionals, have health insurance debts, and they do not have the necessary personal documents, have problems to go to the office or visit a doctor, they do not have the right to receive adequate care. Thereby our participants have identified the need to provide integrated care directly in the community where their clients are located.

This paper was prepared as a part of the project VEGA 1/0322/18 - "Pracujúca chudoba [Working poverty] founded by Scientific Grant Agency of the Ministry of Education, Science, Research and Sport of the Slovak Republic.

\section{References}

[1] R. Park, Am. J. Sociol. 33, 6 (1928)

[2] E. Aisu, Vulnerable and marginalised groups framework for RCIP Project Uganda (2015)

[3] K. Schiffer, E. Schatz, Marginalisation, Social Inclusion and Health (Amsterdam, Correlation Network, 2008)

[4] Monitoring street homelessness in the Old Town of Bratislava. Available: https://www . world-habitat .org/our-programmes/homelessness/

[5] V. Hradecka, I. Hradecky, Bezdomovstvi-extremnivyloucení (Praha, Nadeje, 1996)

[6] M. Stanoev, Bezdomovcijakonositele stigmata a prijemcipomoci. Soc. Prace/Soc. Praca. 15, 5 (2015)

[7] L. Prudky, M. Smidova, Kudykudnu (Praha, Socioklub, 2010)

[8] M. Bartak, Zdravotnystavbezdomovcu a Jehodeterminanty (Ustinad Labem, Univerzita Jana Evangelisty Purkyne, 2011)

[9] A. Geblova, Statist a my 2, 10 (2012)

[10] Act No. 448/2008 Coll. On Social Services an on Amendment of Act No. 455/1991 Coll. on Trade Licenses, as amended

[11] T. Rhodes, Terenniprace s Uzivatelidrog - Zasady a Praxe (Boskovice, Nakladatelstvi Albert, 1999)

[12] WHO, (2016) Integrated care models: an overview. Available: http://www.euro. who.int/__data/assets/pdf_file/0005/322475/Integrated-care-modelsoverview.pdf

[13] J. Hendl, Kvalitativni Vyzkum: Zakladni Metody a Aplikace (Praha, Portal, 2005)

[14] A. Strauss, J. Corbin, Zaklady Kvalitativni Hovyskumu (Boskovice, Nakladatelstvi Albert, 1999)

[15] D.C. Martins, Publ. H. 25, 5 (2008)

[16] J. Blue-Howells, J. McGuire, J. Nakashima, Soc. Work Health Care 43, 3 (2008)

[17] F. Randolph, M. Blasinsky, W. Leginski, L.B. Parker, Psychiatric Ser. 48, 3 (1997) 